\title{
The role of Higher Education in forming loving early childhood educators in Hungary and England.
}

Verity Campbell-Barr, Plymouth Institute of Education, Plymouth University, Drake Circus, Plymouth, PL4 8AA, UK, verity.campbell-barr@plymouth.ac.uk, 01752 585354, (Corresponding author)

Janet Georgeson, Plymouth Institute of Education, Plymouth University, Drake Circus, Plymouth, PL4 8AA, UK, janet.georgeson@plymouth.ac.uk

Anikó Nagy Varga, Faculty of Child and Adult Education, University of Debrecen, Hajdúböszörmény, Hungary, vnaniko@ped.unideb.hu

Acknowledgements:

We would like to thank PedRio at Plymouth University for funding the research, Dr. Magdolna Nemes, Faculty of Child and Adult Education, University of Debrecen, for her support in conducting the fieldwork and translation of Hungarian data and Julie Fletcher, Research Assistant at Plymouth University, for her work in supporting the literature review and analysis for the research. 


\begin{abstract}
:
Those who work in early childhood education are central to securing the overall qualityof servicesand particularly children's experiences. Discussions on qualifications for working in early childhood education often focus on comparisons of structural features, such as qualification level, with much emphasis on Degree Level training. However, existing research demonstrates that those who work in early childhood education often privilege attitudinal features in guiding their work, raising questions over what attitudes are required for early childhood education and how they are developed. This paper presents a mixed method study that considers the attitudes advocated by students undertaking their early childhood education training in England and Hungary and the role of Higher Education in developing them. Whilst identifying a range of attitudes we focus on emotional competence, exploring the differences identified between the views of students in the two countries. We explore how consideration of the cultural context of the two countries can begin to offer some explanations for the differences identified, particularly in regard to policy, history and language and the extent to which these topics should be covered in Higher Education.
\end{abstract}

Key Words: early childhood educators, professionalism, emotions, Higher Education 


\section{The role of Higher Education in forming loving early childhood educators in Hungaryand England}

\section{Introduction}

Across Europe there are variations in the professional development of early childhood educators, but a considered analysis of differences between countries needs to look beyond comparisons of qualification requirements to consider also training approaches within cultural contexts (Oberhuemer et al., 2010). Whilst Higher Education (HE) training is often seen as desirable for quality Early Childhood Education (ECE), it is clear that individual countries are still exploring the function of $\mathrm{HE}$ in developing quality early childhood educators (e.g. Calder 1999; Egan 2009; Einarsdottir 2013; Jensen 2015). We believe there is a need to look beyond comparisons of qualification structures (Urban et al. 2012) in order to have a more considered analysis of the role of $\mathrm{HE}$ in developing early childhood educators. In particular, we draw uponEuropean Lifelong Learning agendas and the role of $\mathrm{HE}$ in developing "a combination of knowledge, skills and attitudes appropriate to the context" (European Commission, 2007: 3). Whilst we do not wish to undermine the importance of knowledge and skills and we also recognise that there is interplay between knowledge, skills and attitudes, we are interested in the role of HE in developing attitudinal competence. Often considerations of the quality of ECE and the workforce within this focus on modernist approaches to measuring and assessing the quality of provision (Campbell-Barr and Leeson, 2016). It is our belief that this means that often attitudinal features can be lost as they are harder to measure, but also that attitudes are difficult constructs for students to make sense of as they form their professional identities. Those undertaking their early childhood education training represent the next generation of the workforce and will be key to securing quality services for children in the future, so it is important to consider how they are structuring their future professional role.

In this paper we draw on a research project involving those undertaking early childhood degrees in two countries: Hungary and England. We set the context for these two countries before summarising findings around the contested nature of attitudes for HE students that have been presented in a previous paper (Campbell-Barr et al. 2015). Here we build on these findings by considering the role of $\mathrm{HE}$ in developing attitudinal competences, whilst appreciating that this happens in relation to the wider social context. Recognising that attitudes are not universal or inevitable but will be shaped by the cultural-historical context, we have adopted a comparative research approach to prompt questions about the taken for granted attitudes in our own cultures (Tobin, 1999: 124) and the language that we use to describe our practice (Alexander, 2000).

\section{Context}

Hungary and England have different approaches to ECE, with regard to the structure, funding and level of qualifications required, that run in parallel with their different political histories. England has a long established liberal democracy, but Hungary became a democratic state again in 1989 following the collapse of Communism in Europe. Since this time Hungary has experienced rapid political and economic developments. Early childhood provision in Hungary is divided between bölcsöde(childcare) services for birth to three years of age and Óvoda (kindergartens) for three to six or seven years of age (parents can delay school entry until seven). ResponsibilityforbölcsödefallsundertheSecretariat of Health, Social and FamilyAffairsintheMinistry of Human Capacities (Emberi Eröforrások Minisztériuma), whilsttheSecreteriat of Education inthesameMinistry has responsibilityfortheÓvoda. There is little provision for those under three due to generous parental leave structures. Óvoda provision is more established and as of the $1^{\text {st }}$ September 2015, each child (but especially those identified as disadvantaged) has to attend the Óvoda from the age of three, with settings being obliged to admit children from their catchment area. Óvoda are largely state run (with a few voluntary sector providers) with funding being 
allocated via local municipalities. There is a National Core Programme that acts as a guide for the ECE practice within the Óvoda, but there is scope (and professional autonomy) for practitioners to adapt it to reflect their local context (Nagy Varga et al., 2015).

In Hungary staff working with children aged three to six (or seven) years of age in a kindergarten have long been required to hold a degree level qualification. Degrees are available for those working with children three and under, but they are not compulsory, so many hold a higher level vocational training qualification. Students can obtain a Higher Level Vocational Training Infant and Child Care degree, which takes two years, to work in crèches. In 2009 a BA programme in infant and early childhood care (csecsemö- és kisgyermeknevelö) was launched and was regarded as an important step, since previously there was no degree level training for those working with children aged birth to three in crèches.

The split model of Hungary (between childcare and early education) is in contrast to England where there has been an attempt to blend together childcare and early education services as exemplified by the one curriculum (the Early Years Foundation Stage; DCSF, 2008; DfE, 2012) for children birth to five. Those delivering ECE are regularly inspected by Ofsted (The Office for Standards in Education, Children's Services and Skills) to ensure that they meet national minimum requirements. Private, voluntary, independent (PVI) and state sectors are all involved in the provision of services, including free early education places (funded by the government) for all three and four years olds and disadvantaged two year olds. Additional hours for two to four year olds and care for younger children can be purchased by parents, with a system of tax credits targeted at workers on low incomes subsiding the cost of childcare.

Qualification requirements vary in England according to the sector and the age of the children with whom the professional is working. For those working with children aged two and under in the PVI sectors, the leader needs to have a Level three and half of all other staff a Level two qualification. In provision for three- and four-year-old children, the same requirements apply as for under twos in the PVI sectors, but in the maintained sector staff are required to hold a Level six (degree) qualification. While degrees are not required in the PVI sectors, financial support to obtain a Level six (first as the Early Years Professional Status and now as the Early Years Teacher) has resulted in a year on year growth in the number of providers having a paid member of staff at Level six, with 13 percent of staff in full daycare, 30 per cent in children's centres and 12 percent in sessional setting (see Brind et al., 2014).

\section{Early childhood educators}

In both countries working in ECE is associated with attitudinal features, but with particular cultural turns.In England there has been much debate around the professionalisation of the workforce, including the desirability of $\mathrm{HE}$ level qualification, with a concern that England is lagging behind other parts of Europe in qualification requirements (Nutbrown, 2012). Whilst those working in ECE broadly welcome the introduction of $\mathrm{HE}$ level training for all sectors, there are concerns over the approach takenby policy makers to up-skill the workforce, that it has been 'done to' the sector rather than with them (Campbell-Barr and Leeson 2016),favouringa managerialist and entrepreneurial discoursethat creates tensions with the ethic of care of being supportive and empathetic that early childhood practitioners uphold (McGillivray, 2008; Osgood, 2004; CampbellBarr, 2014). There is increased criticism that ECE has become technocratic, applying the right techniques at the right times (as exemplified in debates on school readiness and the desirability of assessing children in ECE) and that this neglects more emotional features (Urban, 2008). The result is that early childhood educators find themselves negotiating between competing discourses of performativity and personal constructions of appropriate pedagogy (Wood, 2004). 
In contrast, Hungary appears to be more steeped in an emotional discourse with little evidence of a contested space between the views of policy makers and practitioners as to the preferred models of ECE. In Hungary, demonstrating signs of love (szeretet) is understood as helping children to feel safe (Vekerdy, 2013), fostering intelligent children who will become successful adults.Kovács-Bakosi(2013: 233) identifies applying 'unconditional love extended to all children' as central for ECE in Hungary, with their play based approach offering opportunities for physical interactions between staff and children through games and nursery rhymes (for example). Building on knowledge of child development, a loving environment is about fulfilling attachment needs. Unsafe and insecure attachmentsare associated withdetrimental effects on children's development and well-being (Inántsy-Pap and Máth, 2004). In England, there is also recognition of children's attachment needs, with the 'key-person' approach developed in response to these needs. However, the function of the key person represents another contested space (Elfer 2013; Page and Elfer 2013).Further, whilst in 2008 the Early Years Foundation Stage (the curriculum for ECE in England) discussed that 'children learn to be strong and independent from a base of loving and secure relationships with parents and/or a key person' (DCSF, 2008: 5), a revision in 2012 saw the reference to love removed.

A cultural acceptance of szeretetin ECE in Hungary is evident in a survey of parents in Hungary, which found that parents opted for 'child-loving adults' as the most important feature among the skills required by early childhood educators (Brayfield and Korintus, 2011). This is in contrast to research with parents in England, where it has been reported that whilst love might be discussed in regards to the relationship between practitioners and children, it is not always a term with which parents feel comfortable (Page, 2011).

\section{Emerging early childhood educators}

In our own research (that we will build upon later in the paper) we have identified that the attitudes of those undertaking early childhood degrees are shaped by the cultural context in which they are located (Campbell-Barr et al. 2015). Using both focus groups and an online survey we asked students in England and Hungary to identify the attitudinal competences that they felt were needed for working with young children. A range of attitudes were identified in the focus groups, and students were then asked to rate the importance of these in a survey. We were struck by the variation in what we have identified as'emotional competence': Compassion, Empathy, Affection, Love andEmotional connection with the children (Campbell-Barr et al. 2016). Whilst in Hungary students referred to love freely, in England students cited examples of constraining their emotions. Students used words that they believe are culturally acceptable for ECE;for example, Brayfield and Korntus (2011) discuss how szeretet (love) is one of the oldest words in the Hungarian language and we have already explored how love is seen as a feature of Hungarian ECE. However, we also acknowledge that the political history of Hungary and an emphasis on a Hungarian approach to ECE following the fall of the Iron Curtain (see Nagy Varga et al. 2015) is likely to interplay with this construction of ECE in creating a culturally acceptable way to discuss ECE.

In contrast, the cultural context in England is shaped by the politicisation of ECE, with students demonstrating awareness of a political discourse moulding what it means to work in ECE (CampbellBarr et al., 2015). There are three aspects to the politicisation of ECE that we think are important: one is the favouring of modernist approaches to quality and the workforce that we outlined earlier, whereby features that cannot be measured and assessed (such as love) are lost (Campbell-Barr and Leeson, 2016). The second is a tension between a maternalistic conception of working with young children and a view that anyone can do it, and a construction of professionalism bound by an identifiable body of knowledge (Vincent and Braun 2011; Payler and Locke 2013). The third is that the professionalisation agenda has focussed on those who will lead good quality ECE rather than on the workforce as a whole.Whilst respectful relationships and creating secure attachments are present in the relevant professional standards, the focus is on the child's emotion andforming 
relationships with parents and staff, not the practitioner's emotional involvement with children(e.gWhalley, 2008; Reardon, 2009). Emotional involvement with children is also bound by a child protection discourse that is present in England. This is constructed in part by moral panic around touching, holding and kissing in early childhood settings (Piper and Smith, 2003), but students also identified the Disclosure Barring Service (DBS) check (formally the Criminal Records Bureau check) was building up a culture of fear and suspicion regarding adults who demonstrate affection towards children. In contrast, Hungary does not have a DBS, with students only requiring a certificate of good conduct.

\section{The role of Higher Education}

Having established the contested nature of attitudinal competence in ECE, here we look to explore the role of $\mathrm{HE}$ in supporting students to develop the attitudes appropriate to the context. Rekalidou and Panitsides (2015) have also researched students' beliefs regarding working in ECE, finding that HE was allocated a greater role in developing knowledge and skills than attitudes. DeVore and colleagues (2015) explore the approaches used within one HE institution in American to attune students with the emotional aspects of their future professional role. Colley (2006), exploring lower level qualifications in the UK, also discusses the challenges of developing emotional competence for $E C E$, citing the view that often emotional competence is regarded as innate and beyond the remit of education by those undertaking their training, but highlighting the hidden curriculum within ECE training about being the right kind a person - one who demonstrates the ethic of care that guides ECE that we referred to above.

\section{Methods}

As outlined above, we undertook research with staff who taught on, and students who were studying, early childhood related degrees in two Higher Education (HE) institutions, one in Hungary and one in England (Campbell-Barr et al, 2015). Following a mixed method approach, weused focus groups to explore the attitudes staff and students identified for ECE and used these as the basis of an online survey where students were asked to rate how important they felt the attitudes were. Here, we focus on the role of HE in developing the attitudes. We therefore look at survey responses regarding the different features of HE that students felt were important in developing attitudes, whilst also referring back to the staff and student focus groups.

In total four members of staff and seven students in England and four members of staff and six students in Hungary participated in either a staff or student focus group. There were 66 survey responses from England and 74 from Hungary. Only three males participated in the questionnaire for England, with none from Hungary. There was an average age of 24.4 in England and 24.7 for Hungary. Some of the English students $(\mathrm{N}=24)$ had already undertaken lower level ECE qualifications or had sector-recognised training, such as child protection or first aid. Only 12 Hungarian students identified that they had an ECE qualification prior to undertaking their degree, but for both countries this reflects national qualification requirements. Data were collected in the participants' native language, with the Hungarian data translated into English for analysis.

All staff and students were provided with an ethics protocol outlining the project, details about their right to withdraw, anonymity, that participation was at no consequence for their academic study and how the data would be used to inform teaching and research papers.

\section{Developing Attitudes}

As shown in Figure 1, within the staff and student focus groups a range of approaches to the development of attitudinal competences were identified. Unsurprisingly there was enthusiasm for 
the degrees given that students were investing their time (and, in the English context, money in the form of tuition fees) in their degrees. 
Figure 1: Graph of where students felt that they developed attitudes in relation to HE

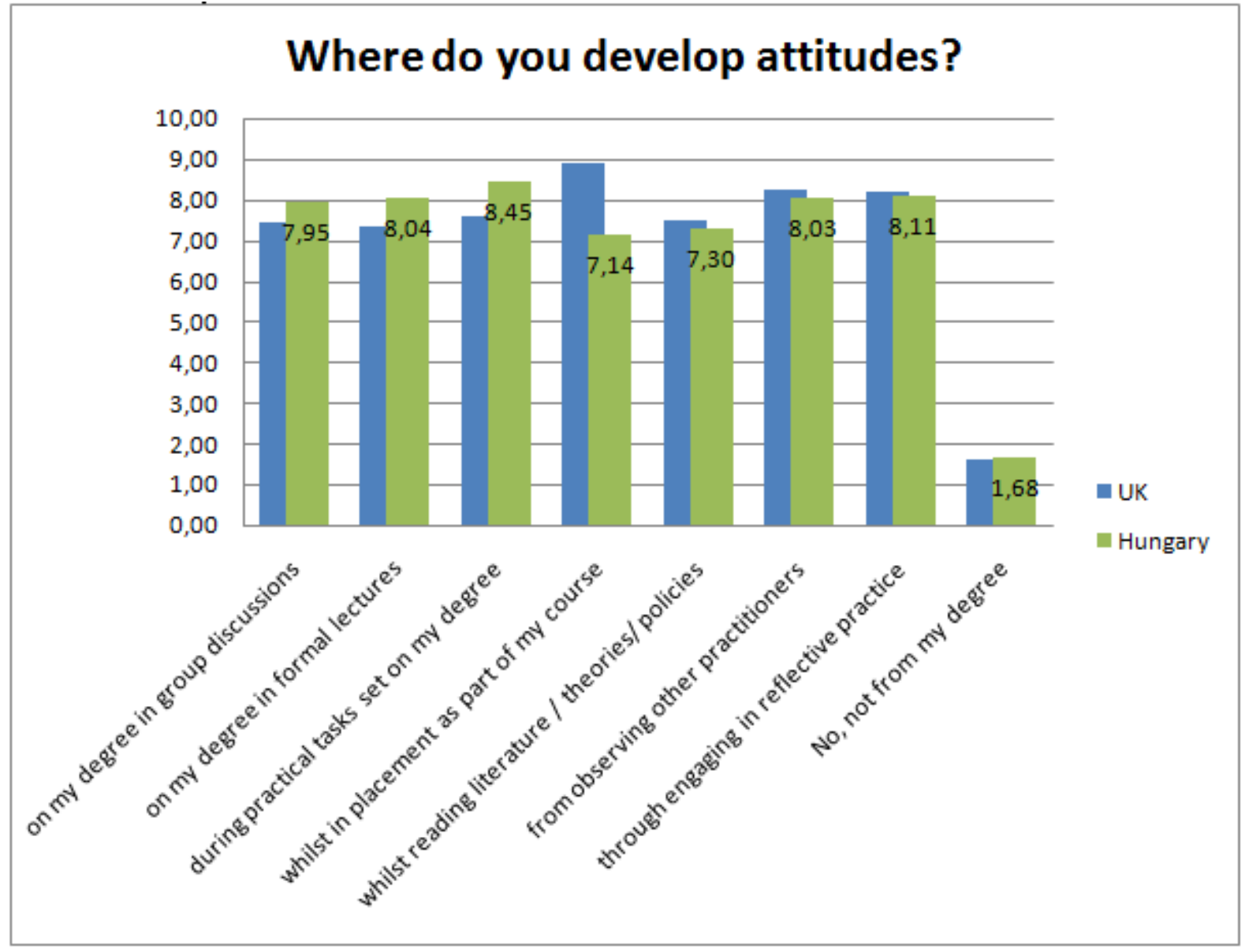

In part the responses reflect the different compositions of the degree that were being offered in the two countries. For example, students in Hungary spend more time observing other practitioners and doing practical tasks than students in England. Also, 'placements' are an English term used to refer to the time spent in practice as a part of the degree. Students are encouraged to establish their own placements and many will opt to do more hours than those required of the degree. In contrast, in Hungary the term 'practicum' is more commonly used, so there may be an issue of translation to explain the differences in the results, but also the practicum is more regular andforms aspects of observation and practical tasks and later discussion lessons; practicum is therefore much more integral to the degree and not always distinguishable from other features.

Whilst there may be some issues around understanding the terms we used in the questionnaire it is evident that students value the 'real life' aspects of their degrees. It is also apparent that students do not rate the theoretical aspects of their degrees as highly, but other research has also identified that students can struggle with the connection between theory and practice (Balduzzi 2011; Onnismaa, Tahkokallio, and Kalliala 2015; Karlsson Lohmander 2015). Egan (2009) explores the role of training in developing professional early childhood educators and the need to offer a range of experiences so that students can consider the different forms of knowledge that inform their professionalism, including both theoretical and attitudinal knowledge. Egan discusses the role of reflection in developing professional identities and certainly reflection was mentioned in the survey and in discussions with students. For example, staff in the English focus group discussed providing safe places for students to talk about their experiences with children, including the more difficult and emotional aspects of their role.

Whilst students emphasised the role of their degrees in developing their attitudinal competences, in the English context it was apparent that they were still coming to terms with forming their 
professional identities. As outlined, the cultural context is shaping the students' experiences, but it has raised the question of whether we really are providing appropriate spaces in which students can reflect on their professionalism. Reflection has become a part of the discourse of ECE; it is seen as a way not only to make sense of practice, but also to move towards professionalism. In the HE context, it is also often a mode of assessment. This prompts questions about what is being reflected and to whom; do students reflect back their thoughts to lecturers to demonstrate that they have learnt something, or to assessors to demonstrate that they meet professional standards, or is it something more personal, to deepen one's understanding of oneself-in-context? Maier-Höfer (2015) exploresthis issue in her use of Wallon's distinction between 'attitude' and 'posture':

The 'attitude', connects the person to her-/himself like a mirror. The attitude supports the stabilisation of the professional identity as an objective opinion on oneself and on one's thoughts, beliefs, convictions and experiences that are transferred cognitively from one situation to the next.

In conducting this piece of research we wonder whether reflection has become something of a shorthand, a term that is used so frequently that it is in danger of losing its meaning, and which can fail to pick up the relational aspects of how understandings of practice are constructed through discussion of and observation of others in practice.

\section{Conclusion}

One difficulty of researching two cases (England and Hungary) is that it can create polarisation in the comparison of cultural context - Hungary as loving, England as not, English ECE as contested, Hungarian as not. We recognise that both our data and discussion are limited in scope, but we feel they offerevidence of how different cultural features come together to shape and inform understandings of ECE and those who work in them. We can see multiple cultural influences history and language, politics and moral panics, but also more subtle understandings around children and childhood which shape culturally appropriate ways to interact with children. From our data we would suggest that those undertaking training to work with young children are in process of developing an understanding of the different cultural features of the communities of practicethey are about to enter. It is therefore important that spaces are provided to discuss and reflect on emerging professional identities, their places in the 'figured worlds' of ECE settings (Hollandet al., 1998). We are cautious in suggesting that self-reflectionalone provides a solution to the development of attitudinal competence, as this does not furnish the actual means of how to reflect. Cultural comparisons can, however, offer insights for students in the process of forming their professional identities; considering and discussing approaches in other countries prompts questions about their own beliefs and practices. Hungary offers an example of where love is not a contested attitude but equally, at a time when Hungary has introduced a right to ECE, England offers a salutary warning about political interest in ECE. Both cases involve attitudinal response and it is becoming clear that attitudes form a feature of pedagogical epistemology in ECE; there is, however, a need to develop betterunderstanding of the role of $\mathrm{HE}$ in developing attitudinal competence. 


\section{$\underline{\text { References }}$}

Alexander, R. J. (2000) Culture and pedagogy: international comparisons in primary education. Malden, MA : Blackwell Publishers.

Bakonyi, A. (2012) Inclusion, Differentiation and Integration - Differentiated Education in the Practice of Early Childhood Education in Early Childhood Education and Care: Specificities of the Hungarian System, Hungarian Institute for Educational Research and Development: http://ec.europa.eu/education/policy/strategic-framework/doc/hungarian-ecec-specificities_en.pdf

Balduzzi, Lucia. 2011. "Promoting professional development in Early Childhood Education and Care (ECEC) field: the role of welcoming newcomers teachers." Review of. Procedia - Social and Behavioral Sciences 15:843-9. doi: http://dx.doi.org/10.1016/j.sbspro.2011.03.196.

Brayfield, A. and M. Korintus (2011). "Early childhood socialization: Societal context and childrearing values in Hungary". Journal of Early Childhood Research 9(3): 262-279.

Brind, R., McGinigal, S., Lewis, J.,Ghezelayagh, S., Ransom, H., Robsone, J., Street, C., and Renton, Z. (2014) Childcare and Early Years Providers Survey 2013, TNS BMRB Report JN 117328, Available at: https://www.gov.uk/government/statistics/childcare-and-early-years-providers-survey-2013,

accessed 22 October 2015

Calder, Pamela. 1999. "The development of early childhood studies degrees in Britain: Future prospects." European Early Childhood Education Research Journal 7 (1):45-67. doi: 10.1080/13502939985208321.

Campbell-Barr, V. (2014) "Constructions of Early Childhood Education and Care Provision": Negotiating Discourses, Contemporary Issues in Early Childhood, 15, 1: 5-17

Campbell-Barr, V., and Leeson, C. (2016)Quality and Leadership in the Early Years. London: Sage.

Campbell-Barr, V., Georgeson, J., and Nagy Varga, A. (2015 forthcoming) "Developing Professional Early Childhood Educators in England and Hungary: where has all the love gone?" European Education

Cohen, L., Manion, L. and Morrison, K. (2011) Research methods in Education, 7th Edition, Oxon: Routledge

Colley, Helen. 2006. "Learning to Labour with Feeling: Class, Gender and Emotion in Childcare Education and Training." Contemporary Issues in Early Childhood 7 (1):15-29. doi: 10.2304/ciec.2006.7.1.15.

CoRe (2011) Competence Requirements in Early Childhood Education and Care: A study for the European Commission Directorate-General for Education and Culture, University of East London and University of Ghent: London, available at: http://ec.europa.eu/education/moreinformation/doc/2011/core_en.pdf 
Department for Children Schools and Families (DCSF) (2008) Statutory Framework for the Early Years Foundation Stage. London: Department for Children Schools and Families.

Department for Education (DfE) (2012) Statutory Framework for the Early Years Foundation Stage: Setting the standards for learning, development and care for children from birth to five. Available online at: https://www.gov.uk/government/publications/early-years-foundation-stage-framework (accessed 31st August, 2014).

DeVore, S., Fox, R., Heimer, L., and Winchell, B. (2015 forthcoming) "Meeting in the Circle: Examining Identity, Attitudes, and Pedagogy in the Context of an Early Childhood Teacher Education Program in the United States" Early Years 35 (4)

Egan, B. A. (2009) "Learning conversations and listening pedagogy: the relationship in student teachers' developing professional identities." European Early Childhood Education Research Journal 17 (1):43-56. doi: 10.1080/13502930802689012.

Einarsdottir, J. (2013) "Early childhood teacher education in the Nordic countries."European Early Childhood Education Research Journal 21 (3):307-10. doi: 10.1080/1350293X.2013.814321.

Elfer, P (2013) "Emotional aspects of nursery policy and practice - progress and prospect." European Early Childhood Education Research Journal. 1-5, published online: http://www.tandfonline.com/doi/full/10.1080/1350293X.2013.798464.

Elfer, P. (2013) "Emotional aspects of nursery policy and practice - progress and prospect."European Early Childhood Education Research Journal1-15. doi: 10.1080/1350293X.2013.798464.

European Commission (2007) KEY COMPETENCES FOR LIFELONG LEARNING European Reference Framework, European Commission: Belgium, available at: http://ec.europa.eu/dgs/education_culture/publ/pdf/II-learning/keycomp_en.pdf

Holland, D., Lachicotte, W., Skinner, D., \& Cain, C. (1998). Identity and agency in cultural worlds. Cambridge, MA: Harvard University Press.

Huskinson, T..Kostadintcheva, K., Greevy, H., Salmon, C., Dobie, S., Medien, K., with Gilby, N., Littlewood, M. and D'Souza, J. (2014) Childcare and early years survey of parents 2012-2013, London: DfE, available at https://www.gov.uk/government/uploads/system/uploads/attachment_data/file/275992/SFR062014_Childcare_and_Early_Years_Survey_of_Parents_2012-13_final.pdf

Inántsy-Pap, J. and Máth, J. (2004) "Coping with parental attachment and preschool social relationships." HUNGARY Psychology2 : pp . 5-25 (in Hungarian)

Jensen, J. (2015) "Placement supervision of pedagogue students in Denmark: the role of university colleges and early childhood centres." Early Years 35 (2):154-67. doi: 10.1080/09575146.2015.1024616.

KarlssonLohmander, M. (2015) "Bridging 'the gap' - linking workplace-based and university-based learning in preschool teacher education in Sweden." Early Years 35 (2):168-83. doi: 10.1080/09575146.2015.1025712. 
Korintus, M. (2008). Early Childhood Education and Care in Hungary: Challenges and Recent Developments. International Journal of Child Care and Education Policy 2(2): 43-52.

KovácsnéBakosi, E. (2013) Hungary: Kindergarten as a public education institution, in Georgeson, J and Payler, J (eds) International Perspectives On Early Childhood Education And Care, Maidenhead: McGraw Hill

McGillivray, G. (2008)“Nannies, nursery nurses and early years professionals: constructions of professional identity in the early years workforce in England." European Early Childhood Education Research Journal 16(2): 242-254.

Maier-Höfer, C. (2015 forthcoming) "Attitude and Passion: Becoming a teacher in Early Childhood Education and Care." Early Years: 35 (4)

Nagy Varga, A. Molnár, B., Pálfi, S., and Szerepi, S. (2015) Hungarian Perspectives on Early Years Workforce Development from the beginning till today in Campbell-Barr, V. and Georgeson, J. International Perspectives on Workforce Development in Early Childhood Education and Care: History, Philosophy and Politics, Critical Publishing, 109-121.

Nutbrown, C. (2012) Foundations for Quality: The independent review of early education and childcare qualifications Final Report. London: DfE. Available online at: https://www.gov.uk/government/publications/nutbrown-review-foundations-for-quality (accessed 31st August, 2014).

Oberhuemer, P., Schreyer, I., and Neuman, M. (2010). Professionals in Early Childhood Education and Care Systems: European Profiles and Perspectives. Barbra Budich Publishers, Leverkusen Opladen.

Onnismaa, E., Tahkokallio, L., and Kalliala, M. (2015)"From university to working life: an analysis of field-based studies in early childhood teacher education and recently graduated kindergarten teachers' transition to work." Early Years 35 (2):197-210. doi: 10.1080/09575146.2015.1011065.

Osgood, J. (2004) "Time to Get Down to Business?" Journal of Early Childhood Research 2(1): 5-24

Osgood, J. (2006)"Professionalism and performativity: the feminist challenge facing early years practitioners." Early Years 26(2): 187 - 199.

Osgood, J. (2010). "Reconstructing professionalism in ECEC: the case for the critically reflective emotional professional". Early Years 30(2): 119 - 133.

Page, J. (2011)“Do mothers want professional carers to love their babies?"Journal of Early Childhood Research 9(3): 310-323.

Page, J., and Elfer, P. (2013) "The emotional complexity of attachment interactions in nursery." Review of. European Early Childhood Education Research Journal 21 (4):553-67. doi: 10.1080/1350293X.2013.766032.

Payler, J,.and Locke, R. (2013). "Disrupting communities of practice? How 'reluctant' practitioners view early years workforce reform in England." European Early Childhood Education Research Journal 21 (1):125-37. doi: 10.1080/1350293X.2012.760340. 
Piper, H. and H. Smith (2003). 'Touch' in educational and child care settings: dilemmas and responses. British Educational Research Journal 29(6): 879-894.

Rekalidou, G. and Panitsides, E. (2015 forthcoming) "What does it take to be a 'successful teacher'? Universities' role in preparing the future early- years workforce." Early Years, 35 (4)

Reardon, D. (2009) Achieving Early Years Professional Status. London: Sage

Rosenthal, M. K. (2003)“Quality in Early Childhood Education and Care: A cultural context”. European Early Childhood Education Research Journal 11(2): 101-116.

Taggart, G. (2011). "Don't we care?: the ethics and emotional labour of early years professionalism. Early Years." An International Journal of Research and Development 31(1): 85-95.

Tobin, J., (1999), "Method and Meaning in Comparative Classroom Ethnography," in Alexander, R. Broadfoot, P. Phillips, D. (eds.)Learning from Comparing. Oxford (UK): Symposium Books.

Tobin, J., Hsueh, Y. \&Karasawa, M. (2009) Preschool in three cultures revisited: China, Japan, and the United States, University of Chicago Press: Chicargo

Urban, M., Vandenbroeck, M., Van Laere, K., Lazzari, A., and Peeters. J. (2012)“Towards Competent Systems in Early Childhood Education and Care: Implications for Policy and Practice."European Journal of Education 47(4): 508-526.

Urban, M. 2008."Dealing with uncertainty: challenges and possibilities for the early childhood profession."European Early Childhood Education Research Journal 16 (2):135-52. doi: 10.1080/13502930802141584.

Vekerdy, T. (2013) Jólszeretni - Tudod-e, hogymilyen a gyereked? Keyhole Publishing

Vincent, C, and Braun, C. 2011. "I think a lot of it is common sense. ...' Early years students, professionalism and the development of a 'vocational habitus'." Journal of Education Policy 26 (6):771-85. doi: 10.1080/02680939.2010.551143.

Vygotsky, L. (1962) Thought and Language. Cambridge, MA: MIT Press (original work published in 1934) 